The BDJ News section accepts items that include general news, latest research and diary events that interest our readers. Press releases or articles may be edited, and should include a colour photograph if possible. Please direct your correspondence to the News Editor, Arveen Bajaj at the BDJ, 64 Wimpole Street WIG 8YS or by e-mail to bdj@bda.org

\section{Changes ahead}

In its recent meeting the GDC agreed a number of matters regarding the OFT Report, Dental Bodies Corporate, PCDs, and the Business of Dentistry.

The GDC agreed that the existing statutory requirement that dental bodies corporate (DBCs) are restricted to dental and ancillary business should be abolished. It added that the existing statutory requirement that the majority of directors of DBCs should be dentists should be amended to require a majority of directors of DBCs to be GDC registrants.

The existing statutory requirement that all operating staff in DBCs must be registrants should be repealed on the grounds that it is unnecessary because the practice of dentistry is already reserved to registrants. It also agreed its intention to extend the business of dentistry to all registrants as soon as new groups of professionals complementary to dentistry are registered and that it should continue to maintain a list of dental bodies corporate.

The changes to the framework for corporate dentistry require amendments to the law and the second Section 60 Order, which is expected next year, will allow for these changes. In the case of the extension of business of dentistry to all registrants, the legislation is intended to be enabling, so that the Council will need to make rules giving effect to this policy.

\section{CPD responses by \\ post}

Due to the recent disruption to the postal service in the UK, all CPD responses will be accepted regardless of when they arrive, including those that arrive after the closing date.

\title{
Wacky races
}

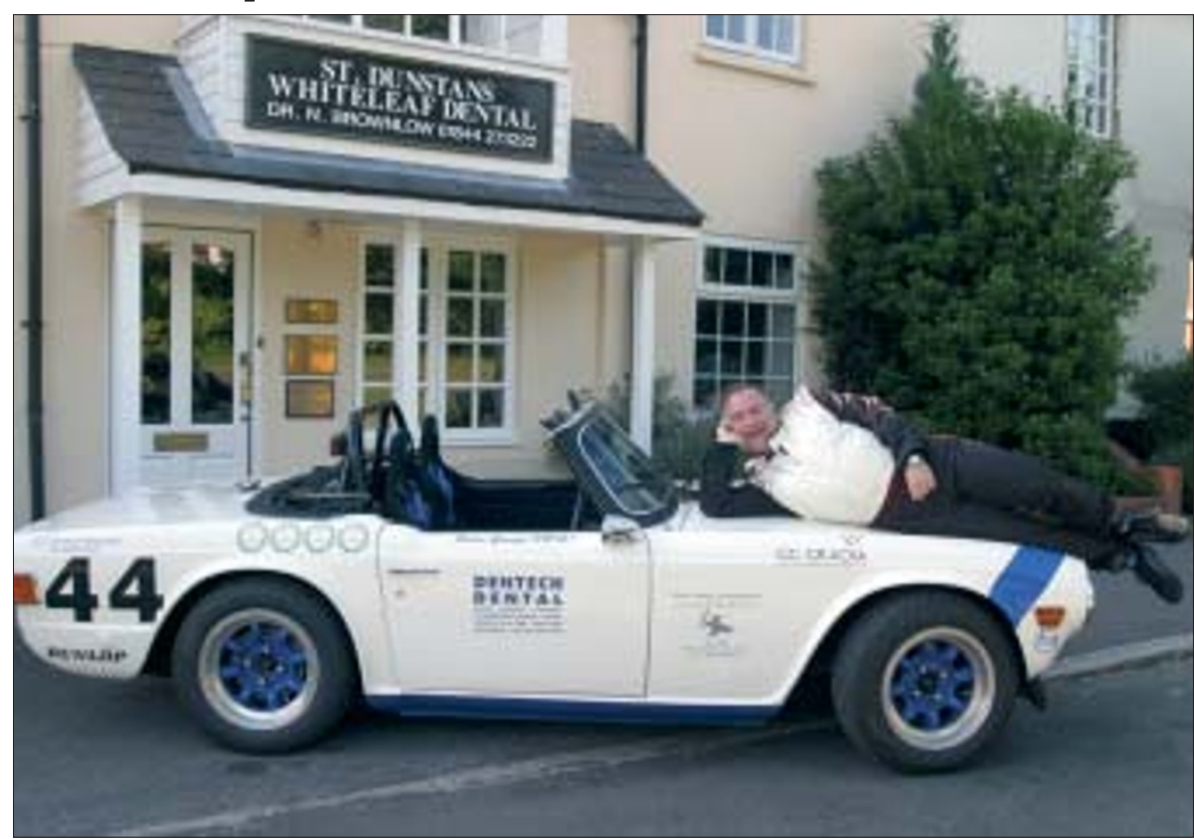

Dental technician Peter Gange raised over $£ 5,500$ for charity together with colleagues in the ninth Castle Coombe Racing Challenge in support of the Stroke Association. The group raised the money by giving paying guests the opportunity to ride 'pillion' in one of their $\mathbf{2 0}$ cars for ten laps. Mr Gange has been involved in the annual event for the past four years and will be supporting its tenth anniversary event next year. (Pictured: Mr Gange and his Triumph TR6)

\section{BDA ends accreditation}

The British Dental Association (BDA) has announced that it is to end involvement in accrediting and recommending dental and oral health care products.

The decision follows a major review of the potential of accreditation and endorsement activity. Options on the table had included a 'recommended' scheme as a successor to the association's accreditation scheme that the BDA had already announced it would be discontinuing.

The BDA will honour existing contractual arrangements until they cease in September 2004.

Citing reasons for the decision, BDA chief executive Ian Wylie said that the Association wanted to explore new ways of working with both the public and the dental industry and added that the commercial partners had been informed about the decision and were looking at innovative approaches to creating more accessible information for the public on dentistry and oral health care.

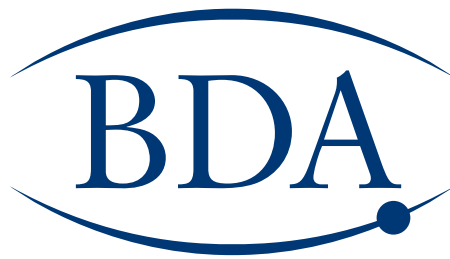




\section{DIARY}

December 2003

The 2003 Premier Symposium

Date: 06.12 .03

Venue: Kings College, London

Contact: Laura Miles, Dental Protection

Tel: +44 (0) 2073991339

E-mail: laura.miles@mps.org.uk

Did you miss this? An update on recent law Date: 12.12.03

Venue: British Dental Association Lecture Theatre, London

Contact: Kath Blackler, Events Office

Tel: +44 (0) 2075634590

E-mail: events@bda.org

March 2004

2nd Asia Pacific Congress on Craniofacial Distraction Osteogenesis

Date: 5-10.03.04

Venue: Maldives

Contact: www.distraction2004.com

E-mail: secretary@distraction2004.com

May 2004

British Dental Conference and Exhibition Date: 06.05.04 - 08-05.04

Contact: Events Office,

British Dental Association

Venue: Bournemouth International

Centre

Tel: +44 (0) 2075634590

Fax: +44 (0) 2075634591

E-mail: events@bda.org

\section{Late dental nurse remembered}

A training bursary was launched last month by community health chiefs to mark the memory of a dedicated 0ldham dental nurse who died earlier this year.

Naveed Maqsood (23), who died of cancer in June, was working at John Scott's dental practice in Lees. Previously, Naveed had spent two years on a bilingual dental nurse training programme run by Oldham Primary Care Trust, which saw him work at six practices in the town centre, Lees and Chadderton areas, along with other placements

The bilingual dental nursing training programme was introduced to improve services to patients speaking Urdu, Bangla or other languages, and to raise awareness among communities of the

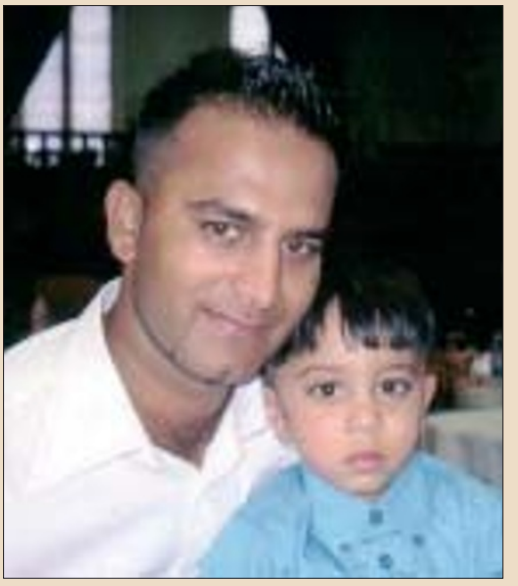

Naveed Maqsood with son Abdullah NHS career options. The training bursary will build on this work by offering additional opportunities to community-based NHS staff who are bilingual, whether they work in dentistry or other areas.

The bursary will provide $£ 1,000$ annually to help fund training opportunities, or purchase training materials including textbooks. The bilingual dental nursing

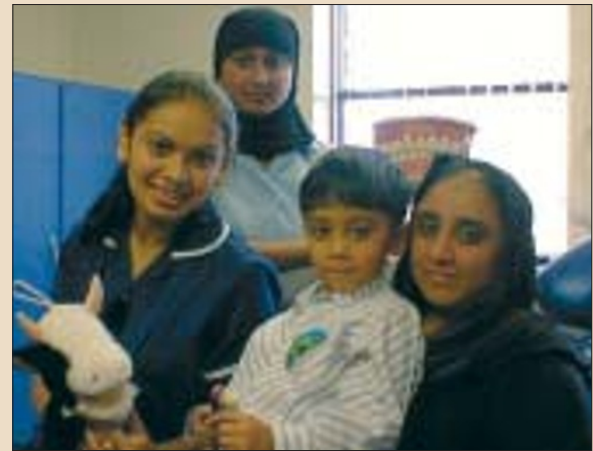

From left to right: Dental nurses Rayhana Khatun and Joohora Begum, who are both on the scheme, Abdullah (Naveed's son) and Jamilla (Naveed's wife) scheme was started in 2001, and was funded by the Oldham NHS Trust.

Oldham PCT took over funding of the scheme when it was created on 1 April 2002. So far, seven trainees have taken part in the scheme, which includes placements at both general dental practices and other specialist centres.

PCT staff who meet criteria including a good knowledge and understanding of issues faced by Oldham's communities and fluency in English and either Urdu, Bangla, Punjabi or Pushto can apply for grants from the Naveed Maqsood training bursary. 


\section{New voice for specialists}

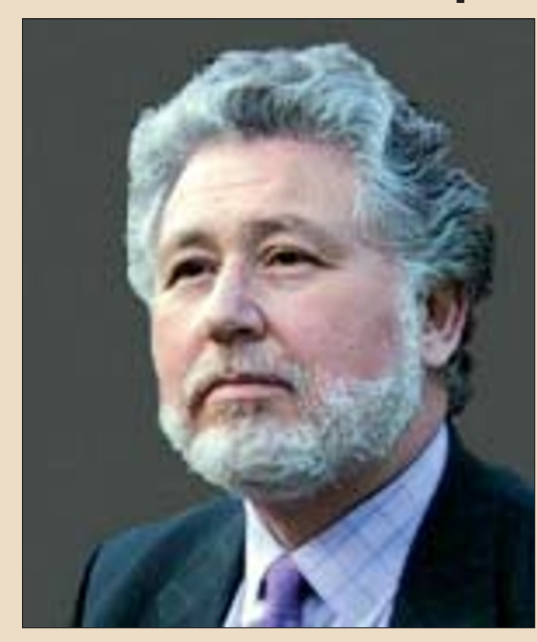

A specialist orthodontic practitioner has been elected to the Board of the Dental Faculty of the Royal College of Surgeons of England.

This is the first occasion that a specialist practitioner from a primary care background has been elected to the Board.

David Barnett is a sole practitioner in Harrow and also a part-time senior clinical lecturer at Guy's Hospital, part of the GKT Dental Institute. He is a former Honorary Secretary of the British Orthodontic Society.

Dr. Barnett plans to try to represent the interests of all specialists working in practice.

\section{Retired GDP gains PhD}

A retired GDP Dr Colin Scott Jones recently received his $\mathrm{PhD}$ at a ceremony that took place at the Institute of Education in September.

Dr Jones worked for and gained the PhD in his retirement. The title of his thesis was was 'Factors Influencing the Finishing of Direct Filling Materials' a subject that every dentist is aware of but of which there is very little dental scientific knowledge.

Dr Jones undertook the research at the Eastman Dental School. He qualified at The Royal Dental Hospital in 1958 and after National Service worked in Weybridge in general practice until his retirement

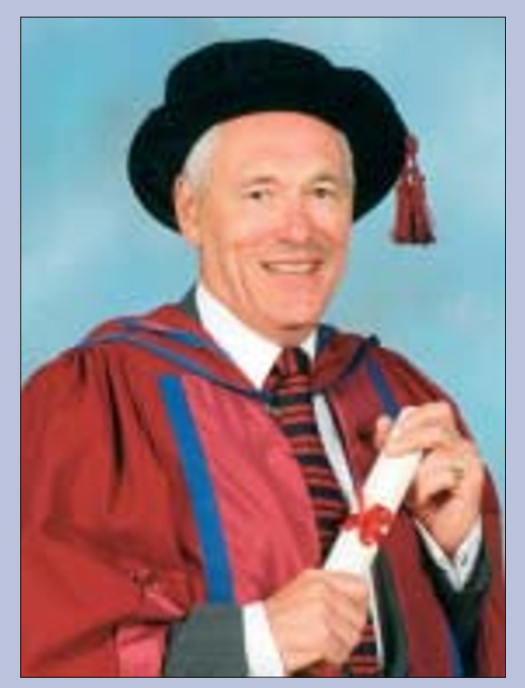

\section{Fond farewells at the ABSTD}

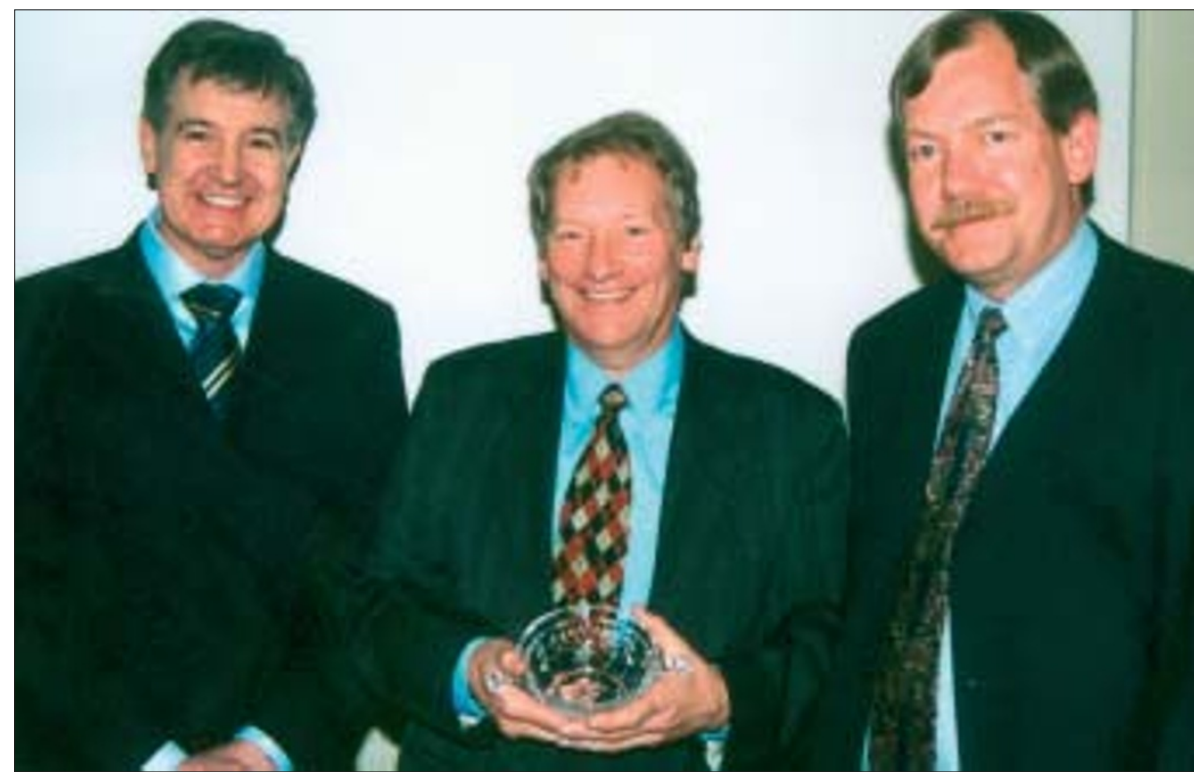

Professor Colin Robinson recently retired as president of the Association of Basic Science Teachers in Dentistry (ABSTD). He was presented with an inscribed quaich to mark the occasion, which took place at the Association's meeting in Sheffield. (Above left to right: Chairman of the Council of Deans of Dental Schools Professor Alan Brook, Professor Robinson and new ABSTD president Professor Tony Smith.) 